\title{
Serum IL-33 Is Elevated in Children with Asthma and Is Associated with Disease Severity
}

\author{
Sedigheh Bahrami Mahneh ${ }^{a} \quad$ Masoud Movahedi $^{b} \quad$ Zahra Aryan $^{d}$ \\ Mohammad Ali Bahar ${ }^{\mathrm{e}}$ Arezou Rezaei ${ }^{\mathrm{c}}$ Maryam Sadr ${ }^{\mathrm{d}}$ \\ Nima Rezaei ${ }^{a, c}$ Universal Scientific Education and Research Network (USERN)

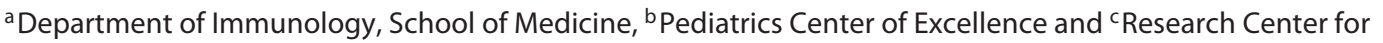 \\ Immunodeficiencies, Children's Medical Center Hospital, and d'Students' Scientific Research Center, \\ Tehran University of Medical Sciences, and e Department of Immunology, School of Medicine, Iran University of \\ Medical Sciences, Tehran, Iran
}

\section{Key Words}

Airway - Airway hyperresponsiveness · Asthma

\begin{abstract}
Background: The role of IL-33, a member of the IL-1 family, in airway hyperresponsiveness and asthma has still to be fully understood. Objectives: This study is aimed at investigating serum IL-33 in children with asthma and its association with asthma severity. Methods: This age- and sex-matched case-control study comprised 61 children with asthma and 63 healthy controls. The mean age of the participants was 9.21 years (range: $6-14)$. Serum IL-33 was measured using ELISA and was compared between children with asthma and controls. In addition, the association of serum IL-33 with asthma severity was investigated. Results: The level of serum IL-33 was significantly higher in children with asthma than in controls ( $15.17 \pm 32.3$ vs. $0.61 \pm 2.16 \mathrm{pg} / \mathrm{ml} ; \mathrm{p}=0.028$ ). It was significantly increased proportionately to asthma severity, namely $9.92 \pm 30.26 \mathrm{pg} / \mathrm{ml}$ in children with mild asth$\mathrm{ma}, 13.68 \pm 29.27 \mathrm{pg} / \mathrm{ml}$ in children with moderate asthma and $31.92 \pm 41.45 \mathrm{pg} / \mathrm{ml}$ in children with severe asthma $(p=$ 0.026). Conclusion: Serum IL-33 is increased in children with asthma and is associated with disease severity.
\end{abstract}

(c) 2016 S. Karger AG, Basel (c) 2016 S. Karger AG, Basel

$1018-2438 / 16 / 1683-0193 \$ 39.50 / 0$

\section{Introduction}

Asthma is a chronic inflammatory airway disease characterized by episodes of reversible airway obstruction, bronchial hyperresponsiveness and chronic pulmonary inflammation [1]. In the last 3 decades, the prevalence of asthma has been increasing, particularly in children. The last estimate of asthma prevalence was 300 million worldwide [1].

The imbalance in immune responses tending towards type 2 and inflammatory responses has been described to be of importance in the immunopathogenesis of asthma in children $[1,2]$. IL-33 is a relatively new member of the IL-1 family of cytokines that mediates both inflammatory and type 2 preallergenic responses. IL-33 secreted by epithelial cells, by binding to its own receptor, ST2, activates the immune system [3]. In mouse models, IL-33 has been found to amplify IgE synthesis, tryptase activity, eotaxin production, histamine release, mast cell degranulation and airway smooth-muscle contractility [4-6].

Recent studies underscored the important role of IL33 in the pathogenesis of the severe steroid-resistant asthma phenotype with [7] or without fungal sensitization [8]. Steroid treatment may reduce IL-13 and other type 2

\section{KARGER 125}

E-Mail karger@karger.com www.karger.com/iaa
Correspondence to: Dr. Nima Rezaei

Children's Medical Center Hospital

Dr. Qarib St, Keshavarz Blvd

Tehran 14194 (Iran)

E-Mail rezaei_nima@tums.ac.ir 
immune responses but does not affect IL-33 expression in fibroblasts and airway smooth-muscle cells taken from airway biopsies of children with severe steroid-resistant asthma $[5,7,8]$. In mouse models of allergic airway disease, the IL-33/ST2 axis induced airway remodeling independent of IL-13 [8]. However, the association of serum IL-33 with asthma severity has still to be studied. We aimed to investigate the serum IL-33 in patients with asthma compared to controls and the association of serum IL-33 with asthma severity.

\section{Materials and Methods}

This age- and sex-matched case-control study was conducted on 124 children under the age of 18 years. The case group comprised 61 children with asthma; 63 healthy children free of any allergic or other chronic diseases were included as controls. Controls were recruited via announcements at schools and in newspapers, while cases with asthma were recruited from the outpatient clinic for asthma and allergy of the Children's Medical Center Hospital. A thorough history was taken and medical records were reviewed for recurrent wheezing, food allergy and atopic dermatitis. Forced expiratory volume in $1 \mathrm{~s}\left(\mathrm{FEV}_{1}\right)$ was measured for all participants. Asthma was diagnosed and classified according to published guidelines [9]. Following diagnosis, asthma severity was categorized into mild (intermittent), moderate and severe. Patients with mild asthma were those with daytime symptoms on $<2$ days and night waking 3-4 times per week, an $\mathrm{FEV}_{1}>80 \%$ of predicted as well as those experiencing minor limitations in their daily activities. Children with severe asthma had frequent daytime symptoms and night waking maybe every night, an $\mathrm{FEV}_{1}<60 \%$ of predicted and experienced major limitations in their daily activities. Patients with moderate asthma had features between these two extremes.

We also categorized the children as having controlled and uncontrolled asthma with respect to their medication needs for control of the disease. Children with controlled asthma had $\leq 2$ daily symptoms or reliever requirements per week and had had no night waking or activity limitation due to asthma during the last month while on adequate treatment. However, uncontrolled asthmatics had frequent daily symptoms and reliever requirements as well as night waking and activity limitations due to their asthma. The participants and their parents received detailed information regarding the study protocol. Informed consent was obtained from the parents of all participants. The institutional review board approved the study and the study protocol was in accordance with the guidelines laid down by the latest version of the Helsinki Declaration (2008).

For the case group, the measurement of serum eosinophil count and IL-33 was done at times other than when the children were admitted for asthma attacks. The controls were free of any acute infectious disease at the time of sample collection. Five milliliters of peripheral blood were collected from both patients and controls and were stored at $-20^{\circ} \mathrm{C}$ for the measurement of IL-33. Serum IL-33 was measured using sandwich enzyme-linked immunosorbent assay (ELISA, eBiosience cat. No. BMS2048). The sensitivity of this ELISA kit was $0.2 \mathrm{pg} / \mathrm{ml}$. The analysis was done according to the manufacturer's guideline.
Table 1. Demographics of the participants

\begin{tabular}{lccr}
\hline Variable & $\begin{array}{l}\text { Asthma patients } \\
(\mathrm{n}=61)\end{array}$ & $\begin{array}{l}\text { Controls } \\
(\mathrm{n}=63)\end{array}$ & $\mathrm{p}$ value \\
\hline Males & $38(62.29)$ & $30(47.61)$ & 0.108 \\
Age, years & $9.44 \pm 2.17$ & $9.97 \pm 2.05$ & 0.164 \\
Eosinophils, \% & $5.05 \pm 3.01$ & $2.14 \pm 1.58$ & $<0.001$ \\
FEV $_{1}, \%$ & $78.2 \pm 8.1$ & $91.1 \pm 8.25$ & $<0.001$ \\
IL-33, pg/ml $^{2}$ & $15.17 \pm 32.3$ & $0.61 \pm 2.16$ & 0.028 \\
\hline
\end{tabular}

Values are $\mathrm{n}(\%)$ or means $\pm \mathrm{SD}$.

Statistical analyses were done using SPPS statistical software v18 (SPSS Inc., Chicago, Ill., USA). The Student t test was used to compare continuous variables and the Fisher exact test for categorical variables between patients with asthma and controls. The Kruskal-Wallis test was used to test associations between IL-33 serum levels and disease severity. $\mathrm{p}<0.05$ was considered statistically significant.

\section{Results}

This case-control study comprised 124 children with a mean age of 9.21 years (range: 6-14 years). Male-to-female ratio was approximately $1: 1$ with a total of 68 boys and 56 girls. The case and control groups were matched with respect to age and sex. Table 1 shows the demographics of participants in the case and control groups. Children with asthma had significantly lower $\mathrm{FEV}_{1}$ than their healthy peers ( $78.2 \pm 8.15$ vs. $91.1 \pm 8.25 \%$; $p<0.001)$, while serum eosinophil count was higher in children with asthma (5.05 \pm 3.01 vs. $2.14 \pm 1.58 \%$; $p<0.001)$. Asthma was mild in 29 , moderate in 24 and severe in 8 children. Serum IL-33 was detectable in 45 children with asthma and in 45 in the control group. We were not able to detect serum IL-33 in 34 of the participants. Children with asthma had a significantly higher level of serum IL-33 than the healthy children $(15.17 \pm 32.3$ vs. $0.61 \pm 2.16 \mathrm{pg} / \mathrm{ml}$; $\mathrm{p}=0.028)$. More severity of asthma and more serum IL33 were observed in children with asthma (fig. 1,2).

\section{Discussion}

We found that children with asthma have higher serum IL-33 levels compared to their healthy peers. The more severe the disease, the more serum IL-33 was detected in blood samples taken from the children with asthma. These findings are in line with the results of pre- 


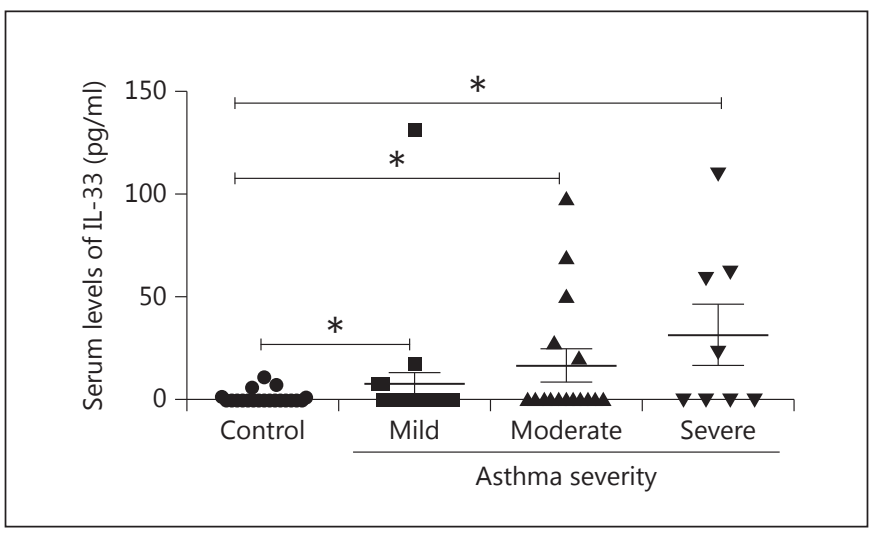

Fig. 1. Serum IL-33 was $9.92 \pm 30.26 \mathrm{pg} / \mathrm{ml}$ in children with mild asthma, $13.68 \pm 29.27 \mathrm{pg} / \mathrm{ml}$ in children with moderate asthma and $31.92 \pm 41.45 \mathrm{pg} / \mathrm{ml}$ in children with severe asthma. Serum IL-33 was the least in asthmatic children with mild disease. However, serum IL-33 was significantly higher in asthmatics than in the control group ( $9.92 \pm 30.26$ vs. $0.61 \pm 2.16 \mathrm{pg} / \mathrm{ml}$; $\mathrm{p}=0.016)$. Similarly, those with severe asthma had significantly higher IL-33 compared to those with moderate and mild asthma. The Kruskal-Wallis test was performed to determine the association of the IL-33 serum levels in the 3 groups with disease severity, which led to significant results $(\mathrm{p}<0.05)$. Patients with moderate and severe asthma had significantly higher serum IL-33 compared to patients with mild asthma $(13.68 \pm 29.27$ vs. $9.92 \pm 30.26 \mathrm{pg} / \mathrm{ml} ; \mathrm{p}=0.03$ and $31.92 \pm 41.45$ vs. $9.92 \pm 30.26 \mathrm{pg} / \mathrm{ml} ; \mathrm{p}=0.002) .{ }^{*} \mathrm{p}<0.05$.

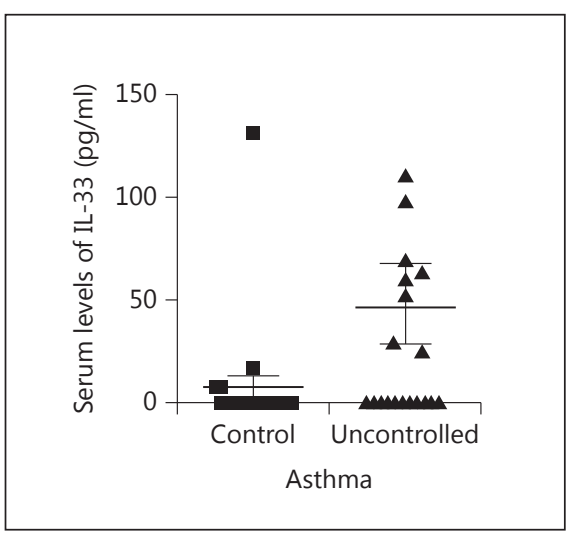

Fig. 2. Participants with uncontrolled asthma had significantly higher serum levels of IL-33 compared to those with controlled asthma (9.92 \pm 30.26 vs. $19.76 \pm 34.04 \mathrm{pg} / \mathrm{ml} ; \mathrm{p}=0.013)$.

vious studies. Guo et al. [10] examined serum IL-33 in 45 patients with asthma and 40 controls, and found that serum IL-33 was higher in the asthma patients. Moreover, serum IL-33 was positively correlated with reticular basement membrane thickening on bronchial biopsies and asthma severity, but negatively correlated with $\mathrm{FEV}_{1}$.
Similarly, Raeiszadeh Jahromi et al. [11] demonstrated that serum IL-33 was higher in patients with asthma than in controls and that it had a negative correlation with $\mathrm{FEV}_{1}$ and forced vital capacity. Interestingly, they showed that serum IL-33 is positively associated with the number of aeroallergen sensitizations. There exists a strong positive correlation between serum IL-33 and induced-sputum IL-33 [12]. The level of IL-33 in sputum is also higher in patients with asthma than in healthy individuals [12].

Serum IL-33 has been shown to be increased in allergic rhinitis more than in allergic asthma $[13,14]$. However, Asaka et al. [14] could not detect IL-33 in sera samples taken from patients with allergic rhinitis. They measured IL-33 in the nasal secretions of study participants instead, and found that IL-33 in the nasal secretions of allergic rhinitis patients was significantly higher than in controls and was also associated with total nasal symptom scores. Similarly, we were not able to detect serum IL-33 in 34 of our 124 participants. Of the children with asthma, serum IL-33 was not detectable in 16 patients with mild disease. However, we found that even children with mild asthma had significantly higher serum IL-33 compared to healthy controls.

The important role of IL-33 in initiating airway hyperresponsiveness and inducing airway remodeling has been shown mainly in studies on animal models. Airway smooth-muscle cells as well as innate type 2 lymphocyte cells and Th2 cells produce IL-33 in response to proinflammatory cytokines and aeroallergen exposure [15]. In addition, type 2 cytokines are released from human $\mathrm{T}$ cells and innate lymphocyte cells cocultured with rhinovirus entirely dependent on IL-33. This finding emphasizes the role of IL-33 in rhinovirus-induced asthma exacerbation [16].

IL-33 also acts as a chemoattractant for Th2 cells, leading to their accumulation in lung tissue and creating a vicious cycle of allergic and inflammatory responses in the airways [17]. Activation of the IL-33/ST2 axis leads to the activation of eosinophils, basophils and mast cells, induces histamine and eotaxin release and increases tryptase activity in the airways and lung parenchyma $[5,18]$. IL-33 has also been found to increased IgE production via IL-4, in a mouse model [4], and to enhance airway smoothmuscle cell contractility [5]. Altogether, IL-33 seems to be a potent inducer of inflammatory and allergic responses leading to airway hyperresponsiveness and asthma.

Increased expression of IL-33 has also been linked to poor control of asthma and the steroid-resistant asthma phenotype [7]. In patients with steroid-resistant asthma, 
steroid treatment may reduce the production of proinflammatory and type 2 cytokines by airway fibroblasts but it does not affect IL-33 expression significantly [8]. IL-33 itself induces the production of collagen and fibronectin by fibroblasts and promotes airway remodeling [8]. These in vitro findings are in line with the results of human studies in which serum IL-33 has been positively correlated with basement membrane thickness on airway biopsies [10]. Given the results of our study and the important role of IL-33 in steroid-resistant asthma, IL-33 can be considered as a marker of asthma severity. However, due to the design of our study, we are unable to draw a causal relationship between increased serum IL-33 and the severity of asthma. Increased IL-33 can still be considered as a consequence of asthma severity, bronchial damage and chronic airway inflammation. In this study, inhaled corticosteroids were the mainstay of therapy, but with an increase in asthma severity, a combination of long-acting $\beta_{2}$ agonists and leukotriene receptor antago- nists was used. Unfortunately, we did not record the exact medications used and their dosage. Hence, another limitation of this study is the absence of investigation of the possible effect of each medication on serum IL-33. The strengths of the study are its concise design and the matching of cases and controls. However, several limitations should be acknowledged. As stated, no causality link can be drawn between the increased expression of IL-33 and asthma severity. Moreover, serum IL-33 was undetectable in a considerable number of participants; this lowers the power of the study. Further studies are needed to shed light on the exact role of IL-33 in severe asthma and to pave the way for more efficacious therapies.

\section{Acknowledgement}

This study was supported by a grant from the Tehran University of Medical Sciences (91-04-30-19310).

\section{References}

1 Aryan Z, Compalati E, Canonica GW, Rezaei $\mathrm{N}$ : Allergen-specific immunotherapy in asthmatic children: from the basis to clinical applications. Expert Rev Vaccines 2013;12:639659.

2 Aryan Z, Holgate ST, Radzioch D, Rezaei N: A new era of targeting the ancient gatekeepers of the immune system: Toll-like agonists in the treatment of allergic rhinitis and asthma. Int Arch Allergy Immunol 2014;164:46-63.

3 Moussion C, Ortega N, Girard JP: The IL-1like cytokine IL-33 is constitutively expressed in the nucleus of endothelial cells and epithelial cells in vivo: a novel 'alarmin'? PLoS One 2008;3:e3331.

4 Komai-Koma M, Brombacher F, Pushparaj PN, Arendse B, McSharry C, Alexander J, Chaudhuri R, Thomson NC, McKenzie AN, McInnes I, Liew FY, Xu D: Interleukin-33 amplifies IgE synthesis and triggers mast cell degranulation via interleukin-4 in naive mice. Allergy 2012;67:1118-1126.

5 Kaur D, Gomez E, Doe C, Berair R, Woodman L, Saunders R, Hollins F, Rose FR, Amrani Y, May R, Kearley J, Humbles A, Cohen ES, Brightling CE: IL-33 drives airway hyperresponsiveness through IL-13-mediated mast cell: airway smooth muscle crosstalk. Allergy 2015;70:556-567.

6 Kurokawa M, Matsukura S, Kawaguchi M, Ieki K, Suzuki S, Odaka M, Watanabe S, Homma T, Sato M, Yamaguchi M, Takeuchi H, Adachi M: Expression and effects of IL-33 and ST2 in allergic bronchial asthma: IL-33 induces eotaxin production in lung fibroblasts. Int Arch Allergy Immunol 2011;155(suppl 1):1220.
7 Castanhinha S, Sherburn R, Walker S, Gupta A, Bossley CJ, Buckley J, Ullmann N, Grychtol R, Campbell G, Maglione M, Koo S, Fleming L, Gregory L, Snelgrove RJ, Bush A, Lloyd CM, Saglani S: Pediatric severe asthma with fungal sensitization is mediated by steroidresistant IL-33. J Allergy Clin Immunol 2015; 136:312-322.

8 Saglani S, Lui S, Ullmann N, Campbell GA, Sherburn RT, Mathie SA, Denney L, Bossley CJ, Oates T, Walker SA, Bush A, Lloyd CM: IL-33 promotes airway remodeling in pediatric patients with severe steroid-resistant asthma. J Allergy Clin Immunol 2013;132:676685 e613.

9 Bacharier LB, Boner A, Carlsen KH, Eigenmann PA, Frischer T, Gotz M, Helms PJ, Hunt J, Liu A, Papadopoulos N, Platts-Mills T, Pohunek P, Simons FE, Valovirta E, Wahn U, Wildhaber J; European Pediatric Asthma Group: Diagnosis and treatment of asthma in childhood: a PRACTALL consensus report. Allergy 2008;63:5-34.

10 Guo Z, Wu J, Zhao J, Liu F, Chen Y, Bi L, Liu S, Dong L: IL-33 promotes airway remodeling and is a marker of asthma disease severity. J Asthma 2014;51:863-869.

11 Raeiszadeh Jahromi S, Mahesh PA, Jayaraj BS, Madhunapantula SR, Holla AD, Vishweswaraiah S, Ramachandra NB: Serum levels of IL-10, IL-17f and IL-33 in patients with asthma: a case-control study. J Asthma 2014; 51:1004-1013.

12 Hamzaoui A, Berraies A, Kaabachi W, Haifa M, Ammar J, Kamel H: Induced sputum levels of IL-33 and soluble ST2 in young asthmatic children. J Asthma 2013;50:803-809.
13 Gluck J, Rymarczyk B, Rogala B: Serum IL-33 but not ST2 level is elevated in intermittent allergic rhinitis and is a marker of the disease severity. Inflamm Res 2012;61:547-550.

14 Asaka D, Yoshikawa M, Nakayama T, Yoshimura T, Moriyama H, Otori N: Elevated levels of interleukin-33 in the nasal secretions of patients with allergic rhinitis. Int Arch Allergy Immunol 2012;158(suppl 1):47-50.

15 Prefontaine D, Lajoie-Kadoch S, Foley S, Audusseau S, Olivenstein R, Halayko AJ, Lemiere C, Martin JG, Hamid Q: Increased expression of IL-33 in severe asthma: evidence of expression by airway smooth muscle cells. J Immunol 2009; 183:5094-5103.

16 Jackson DJ, Makrinioti H, Rana BM, Shamji BW, Trujillo-Torralbo MB, Footitt J, Jerico D-R, Telcian AG, Nikonova A, Zhu J, Aniscenko J, Gogsadze L, Bakhsoliani E, Traub S, Dhariwal J, Porter J, Hunt D, Hunt T, Hunt T, Stanciu LA, Khaitov M, Bartlett NW, Edwards MR, Kon OM, Mallia P, Papadopoulos NG, Akdis CA, Westwick J, Edwards MJ, Cousins DJ, Walton RP, Johnston SL: IL-33-dependent type 2 inflammation during rhinovirus-induced asthma exacerbations in vivo. Am J Respir Crit Care Med 2014;190:1373-1382.

17 Yagami A, Orihara K, Morita H, Futamura K, Hashimoto N, Matsumoto K, Saito H, Matsuda A: IL-33 mediates inflammatory responses in human lung tissue cells. J Immunol 2010;185:5743-5750.

18 Pecaric-Petkovic T, Didichenko SA, Kaempfer S, Spiegl N, Dahinden CA: Human basophils and eosinophils are the direct target leukocytes of the novel IL-1 family member IL33. Blood 2009;113:1526-1534. 